\title{
Polyoxometalate-based 3D porous framework with inorganic molecular nanocage units
}

\author{
SHAOBIN LI*, ZIHAO LI, JINGYU ZHANG, ZHENGNAN SU, SHIYING QI, SHIHONG GUO \\ and XIAOGUO TAN \\ College of Materials Science and Engineering, Qiqihar University, Qiqihar 161006, China \\ Email: qqhrlsb1022@126.com
}

MS received 25 November 2016; revised 9 February 2017; accepted 22 March 2017

\begin{abstract}
A new polyoxometalate-based 3D porous framework with inorganic molecular nanocage unit, $\left(\mathrm{H}_{2}\right.$ dap) $\left[\mathrm{K}\left(\mathrm{H}_{2} \mathrm{O}\right)_{2}\left(\mathrm{~V}_{10} \mathrm{O}_{28}\right)_{0.5}\right]$ (1) (dap = 1,2-diaminopropane), has been synthesized and characterized by routine methods. In $\mathbf{1}$, the decavanadate clusters, as twelve-dentate connectors, link eight potassium ions to form a 3D porous framework with inorganic molecular cage units. There are two dap ligand molecules occupying in each inorganic molecular cage. Furthermore, the electrochemical properties of $\mathbf{1}$ were studied, which indicate that $\mathbf{1}$ has a good electrocatalytic activity towards reduction of iodate $\left(\mathrm{IO}_{3}^{-}\right)$ascribed to the $\mathrm{V}$-center.
\end{abstract}

Keywords. Polyoxometalates; inorganic nanocage; 3d porous framework; electrochemistry; electrocatalysis.

\section{Introduction}

Molecular cage is of great interest not only because of their well-defined cavities and structural characteristics that can incorporate various guest species for chemical reactivity, but also for their potential applications in catalysis, gas separation and storage. ${ }^{1-7}$ During the past few decades, self-assembly of molecular cages with various sizes and shapes has been extensively explored. Polyoxometalates (POMs), as a large family of metaloxygen clusters, have been extensively studied due not only to their unmatched structural types and attractive properties such as a controllable shape, size, high negative charge, and nucleophilic oxygen-enriched surface, but also for various potential applications in catalysis, medicine and materials science. ${ }^{8-17}$ The design and synthesis of POM-based molecular cages might merge POM's merits to generate extra-large nanosized cages with special properties. Thus, the POM-based molecular cages have gained the attention of chemists. To date, thanks to the work of POM chemists, some novel POM-based molecular cages have been successfully synthesized. It is notable that $\mathrm{Lu}$ et al., successfully made a discrete adamantane-like cage in $2010 ;{ }^{18}$ in the same year, Yang et al., reported a discrete POM-based organic cage based $\mathrm{Ni}_{6}$-substituted POMs ${ }^{19}$ and Wang et al., reported a 3D porous framework with two types of cubic cages. ${ }^{20}$ Recently, Su et al., obtained a cage struc-

\footnotetext{
*For correspondence
}

ture based on $\mathrm{P}_{4} \mathrm{Zn}_{16}$ cluster, ${ }^{21}$ and Niu et al., isolated a inorganic-organic molecular cage based on $\mathrm{AsMo}_{6}$ cluster. ${ }^{22}$ Inspired by these pioneering work, in our present work, we report POM-based molecular cages.

Herein, we report the preparation and structure of a new polyoxometalate-based $3 \mathrm{D}$ porous framework with inorganic molecular cage units, $\left(\mathrm{H}_{2}\right.$ dap $)\left[\mathrm{K}\left(\mathrm{H}_{2} \mathrm{O}\right)_{2}\right.$ $\left.\left(\mathrm{V}_{10} \mathrm{O}_{28}\right)_{0.5}\right]$ (1) (dap = 1,2-diaminopropane), which exhibits a $(4,8)$-connected 3D framework with a novel $\left(4^{6}\right)\left(4^{11} \cdot 6^{13} \cdot 8^{4}\right)$ topology. To the best of our knowledge, to date, it represents the first decavanadate-based $3 \mathrm{D}$ porous framework with inorganic molecular cage unit.

\section{Experimental}

\subsection{Materials and methods}

All chemicals were of reagent grade and used without further purification. Elemental analyses $(\mathrm{C}, \mathrm{H}$ and $\mathrm{N})$ were performed on a Perkin-Elmer $2400 \mathrm{CHN}$ Elemental Analyzer. The FT-IR spectra were recorded in $\mathrm{KBr}$ pellets in the range $4000-400 \mathrm{~cm}^{-1}$ with a Nicolet AVATAR FT-IR360 spectrometer. X-ray photoelectron spectrum (XPS) was recorded on an ESCALAB-MKII spectrometer. A CHI660 electrochemical workstation was used for controlled electrochemical measurements and data collection. A conventional threeelectrode system was used, with carbon paste electrode (CPE) as working electrode, commercial $\mathrm{Ag} / \mathrm{AgCl}$ as reference electrode and twisted platinum wire as counter electrode. 


\subsection{Synthesis of compound 1}

$\mathrm{NaVO}_{3}(0.26 \mathrm{~g}, 2.13 \mathrm{mmol})$ and $\mathrm{H}_{3} \mathrm{BO}_{3}(0.16 \mathrm{~g}, 2.58 \mathrm{mmol})$ were dissolved in water $(15 \mathrm{~mL})$, and stirred for $1 \mathrm{~h}$ at $80^{\circ} \mathrm{C} . \mathrm{KCl}(0.36 \mathrm{~g}, 4.83 \mathrm{mmol})$ and 1,2-diaminopropane (dap) $(0.3 \mathrm{~mL})$ were added to the above solution at $80^{\circ} \mathrm{C}$. Stirred for $2 \mathrm{~h}$ with a starting $\mathrm{pH}=4.85$, adjusted by $1 \mathrm{M}$ $\mathrm{CH}_{3} \mathrm{COOH}$. Then, the solution was cooled to room temperature and filtered. Slow evaporation at room temperature resulted in yellow crystals of 1 after 10 days with a yield 51\% based on V. Anal. calcd. for 1: H, 2.40; C, 5.73; N, 4.45; K, 6.22; V, 40.50 (\%). Found: H, 2.31; C, 5.84; N, 4.34; K, 6.34; V, $40.84(\%)$.

\section{$2.3 X$ X-ray crystallographic study}

A single crystal of $\mathbf{1}$ was carefully selected for single-crystal $\mathrm{X}$-ray diffraction analysis. Data collection was performed on a Rigaku RAXIS-RAPID equipped with a narrow-focus, $5.4 \mathrm{~kW}$ sealed tube X-ray source (graphite-monochromated Mo $K \alpha$ radiation, $\lambda=0.71073 \AA$ ). The data was collected at $293 \mathrm{~K}$. The data processing was accomplished with the PROCESS-AUTO processing program. The structure of $\mathbf{1}$ was solved by direct methods and refined by full-matrix least-squares on $F^{2}$ using the SHELXTL 97 crystallographic software package. ${ }^{23}$ Anisotropic displacement parameters were used to refine all non-hydrogen atoms. The organic hydrogen atoms were generated geometrically. The hydrogen atoms of the water molecule in $\mathbf{1}$ could not be introduced in the refinement but were included in the structure factor calculation. Details of the X-ray structure analysis are given in Table 1. Selected bond lengths and angles are listed in Table S1 (in Supplementary Information). Crystal data and structure refinement, bond lengths and angles, and anisotropic displacement parameters are available in supplementary crystallographic data.

\section{Results and Discussion}

It is worth noting that the use of boric acid was necessary in the synthesis of compound $\mathbf{1}$, although it is not present in the final structure; we could not obtain compound $\mathbf{1}$ without it.

Table 1. Crystal data and structure refinement for $\mathbf{1}$.

\begin{tabular}{|c|c|}
\hline Empirical formula & $\mathrm{C}_{3} \mathrm{H}_{16} \mathrm{KN}_{2} \mathrm{O}_{16} \mathrm{~V}_{5}$ \\
\hline Formula weight & 629.93 \\
\hline Color & Yellow \\
\hline Crystal. size, $\mathrm{mm}^{3}$ & $0.36 \times 0.32 \times 0.28$ \\
\hline Crystal system & Triclinic \\
\hline Space group & $P-1$ \\
\hline $\mathrm{a} \AA$ & $8.659(5)$ \\
\hline $\mathrm{b} \AA$ & $10.320(5)$ \\
\hline c $\AA$ & $10.788(5)$ \\
\hline$\alpha, \operatorname{deg}$ & $69.251(5)$ \\
\hline$\beta, \operatorname{deg}$ & $78.746(5)$ \\
\hline$\gamma, \operatorname{deg}$ & $66.233(5)$ \\
\hline Volume, $\AA^{3}$ & $823.5(7)$ \\
\hline$Z$ & 2 \\
\hline Dc, $\mathrm{g} \mathrm{cm}^{-3}$ & 2.516 \\
\hline$\mu(\operatorname{Mo} K \alpha), \mathrm{mm}^{-1}$ & 3.072 \\
\hline $\mathrm{F}(000)$ & 608.0 \\
\hline$h k l$ Range & $-11 \leq h \leq 8,-13 \leq k \leq 13,-10 \leq l \leq 14$ \\
\hline Refl. measured/unique & $6007 \overline{4} 07 \overline{6}$ \\
\hline $\mathrm{R}_{\text {int }}$ & 0.0136 \\
\hline Data/parameters & $4050 / 245$ \\
\hline GOF on F2 & 0.947 \\
\hline $\mathrm{R}_{1}, \mathrm{wR}_{2}[\mathrm{I}>2 \sigma(I)]^{\mathrm{a}, \mathrm{b}}$ & $0.0278 / 0.0792$ \\
\hline $\mathrm{R}_{1}$, wR $\mathrm{R}_{2}$ (all data) & $0.0347 / 0.0831$ \\
\hline$\Delta \rho_{\text {fin }}(\max / \min )$, e $\AA^{-3}$ & $0.724 /-0.713$ \\
\hline Highest peak & 0.72 \\
\hline Deepest hole & -0.71 \\
\hline
\end{tabular}




\subsection{Description of crystal structure}

The single-crystal $\mathrm{X}$-ray diffraction analysis has revealed that $\mathbf{1}$ consists of one $\mathrm{V}_{10} \mathrm{O}_{28}^{6-}$ anion (abbreviated as $\mathrm{V}_{10}$ ), one $\mathrm{K}^{+}$cation, one biprotonated dap ligand and two coordinated water molecules, as shown in Figure 1 . The $\mathrm{V}$ atoms are in +5 oxidation state confirmed by BVS calculations ${ }^{24}$ (Table S2) and XPS spectrum (Figure S1, in Supplementary Information).

There is one crystallographically independent $\mathrm{K}$ ion in $\mathbf{1}$, which interacts with eight $\mathrm{O}$ atoms, two from water molecules and six from four $\mathrm{V}_{10}$ anions (Figure 2a). The bond lengths and angles around the $\mathrm{K}$ ion are in the ranges of 2.763(2)-3.034(2) $\AA(\mathrm{K}-$ O) and $54.11(6)^{\circ}-163.58(4)^{\circ}(\mathrm{O}-\mathrm{K}-\mathrm{O})$. All of these bond lengths and angles are within the normal ranges observed in other K-containing complexes. ${ }^{25}$ The centrosymmetric polyanion consists of five independent $\left[\mathrm{VO}_{6}\right]$, sharing edges, and has approximate $D_{2 h}$ symmetry. The bond lengths and angles of the decavanadate anion show a similar trend to those reported in the literature. ${ }^{26,27}$ The asymmetric unit in the crystal structure of 1 consists of one crystallographically independent monovalent lacunary Lindqvist anion. Two monovalent lacunary Lindqvist anions are linked through sharing of two $\left[\mathrm{VO}_{6}\right]$ that make up of the decavanadate anion. As shown in Figure $2 b$, each $V_{10}$ cluster acts as a twelvedentate inorganic ligand, covalently bonded to eight $\mathrm{K}$ ions $\left(\mathrm{K} 1, \mathrm{~K} 1^{\# 1}, \mathrm{~K} 1^{\# 2}, \mathrm{~K} 1^{\# 3}, \mathrm{~K} 1^{\# 4}, \mathrm{~K} 1^{\# 5}, \mathrm{~K} 1^{\# 6}\right.$ and $\mathrm{K} 1^{\# 7}$ ).

One of the structural features of $\mathbf{1}$ is that each $\mathrm{V}_{10}$ cluster, as twelve-dentate inorganic ligand, links eight potassium ions to form a 3D porous framework. From the topological view, each $\mathrm{K} 1$ cation is considered as

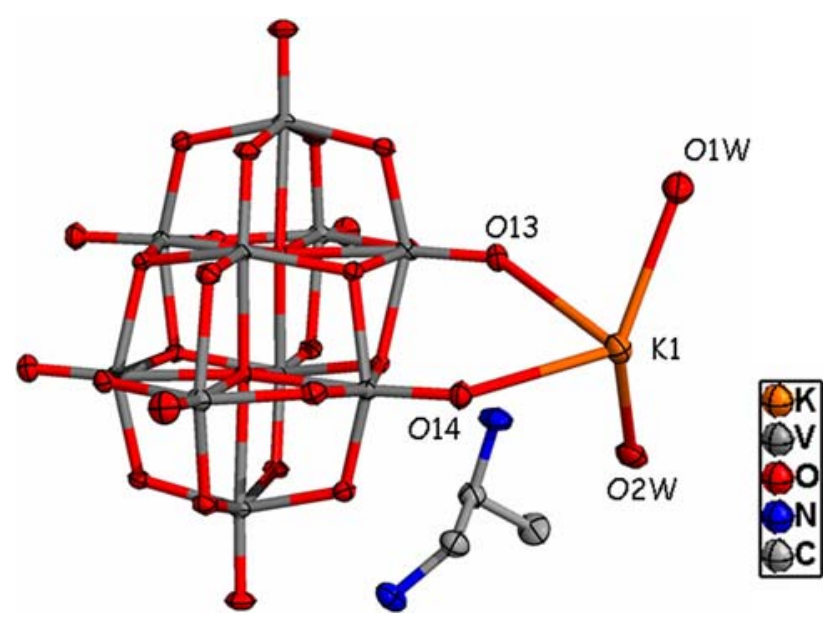

Figure 1. ORTEP drawing of $\mathbf{1}$ with displacement ellipsoids set at 50\% probability. Hydrogen atoms are omitted for clarity. a 4-connected node and $\mathrm{V}_{10}$ cluster is considered as 8connected node. The structure of $\mathbf{1}$ can be simplified as a novel 3D $(4,8)$-connected framework with a $\left(4^{6}\right)\left(4^{11}\right.$. $61^{3} \cdot 8^{4}$ ) topology (Figure 3 ). The more aesthetically pleasing structural feature is the inorganic molecular cage with an inner cavity diameter of approximately $5.68 \AA$, which is constructed by six K cations linking six $\mathrm{V}_{10}$ clusters (Figure $2 \mathrm{~d}$ ). Interestingly, there are two free dap ligands in each inorganic molecular cage. To the best of our knowledge, it represents the first example of $\mathrm{V}_{10^{-}}$ based 3D porous framework with inorganic molecular cage units, to date.

\subsection{IR spectrum}

The IR spectrum of compound 1 (Figure S2 in SI) exhibits the characteristic peaks at 953, 832 and 745 $\mathrm{cm}^{-1}$, which are attributed to $v\left(\mathrm{~V}-\mathrm{O}_{\mathrm{t}}\right)$ and $v_{\mathrm{as}}(\mathrm{V}-$ $\left.\mathrm{O}_{\mathrm{b}}-\mathrm{V}\right)$, respectively. Compared to the typical decavanadate cluster, compound $\mathbf{1}$ has similar peaks in the range of 730-960 $\mathrm{cm}^{-1}$ except for slight shifts of peaks due to the interactions between the $\mathrm{V}_{10}$ anions and the $\mathrm{K}^{+}$in the solid state, which indicates that the $\mathrm{V}_{10}$ cluster in the title compound still retains the basic structure of decavanadate anion. ${ }^{28}$ The bands in the region of $1631-1113 \mathrm{~cm}^{-1}$ could be ascribed to the characteristic peaks of dap ligand. Additionally, the broad band at $3461 \mathrm{~cm}^{-1}$ is associated with the water molecule.

\subsection{Electrochemical properties}

In order to study the redox properties of title compound, the cyclic voltammetric behavior of $\mathbf{1}$ was measured in $0.5 \mathrm{M} \mathrm{H}_{2} \mathrm{SO}_{4}-\mathrm{Na}_{2} \mathrm{SO}_{4}$ solution $(\mathrm{pH}=2.75,10 \mathrm{~mL})$. In the potential range from +0.40 to $-0.1 \mathrm{~V}$, there are two pairs of redox peaks (I-I', II-II'), and the average peak potentials, $E_{1 / 2}=(E \mathrm{pc}+E \mathrm{pa}) / 2$, are $c a$. 0.16 and $0.08 \mathrm{~V}$, which are ascribed to one-electron vanadium-centered $\mathrm{V}^{\mathrm{V}} \rightarrow \mathrm{V}^{\mathrm{IV}}$ redox process. ${ }^{29,30} \mathrm{As}$ shown in the inset of Figure 4, when the scan rates are varied from 0.1 to $0.6 \mathrm{~V} \mathrm{~s}^{-1}$, the peak potentials change gradually: the cathodic peak potentials shift toward the negative direction and the corresponding anodic peak potentials to the positive direction with increasing scan rates. The peak currents are proportional to the scan rate, which indicates that the redox processes are surfacecontrolled. ${ }^{31}$

The POMs have been exploited extensively in electrocatalytic reactions and in applications such as biosensors and fuel cells. ${ }^{32,33}$ Here, the reduction of $\mathrm{IO}_{3}^{-}$ was chosen as a test reaction to study the electrocatalytic activity of $\mathbf{1}$. As shown in Figure 5, it 

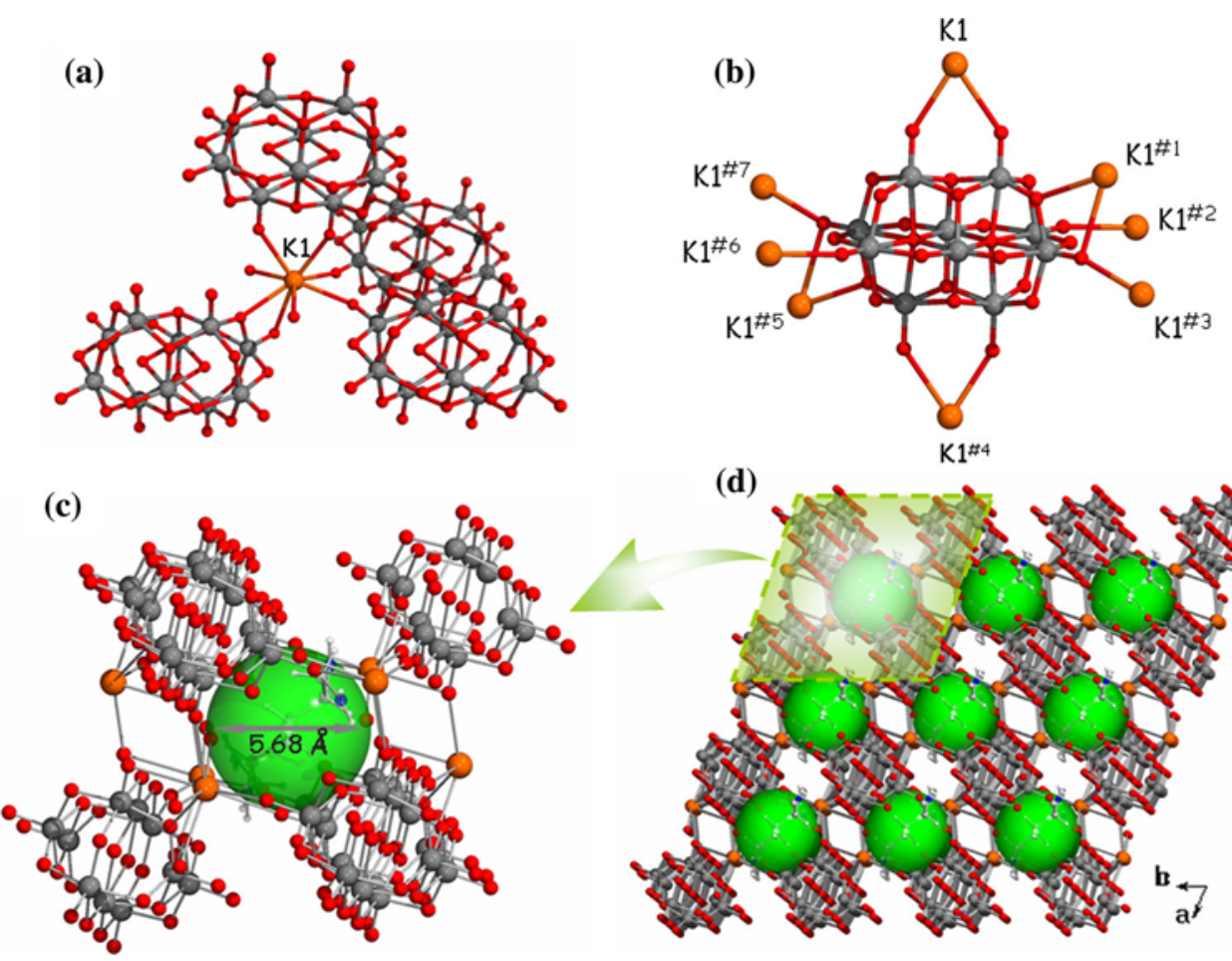

(d)

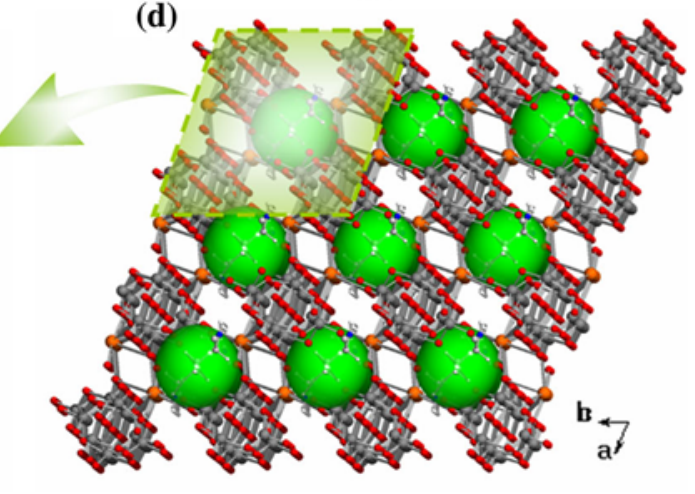

Figure 2. (a, b) The coordination relation between the $\mathrm{K}$ cation and $\mathrm{V}_{10}$ cluster; (c) the 3D porous framework; and (d) the inorganic molecular cage.

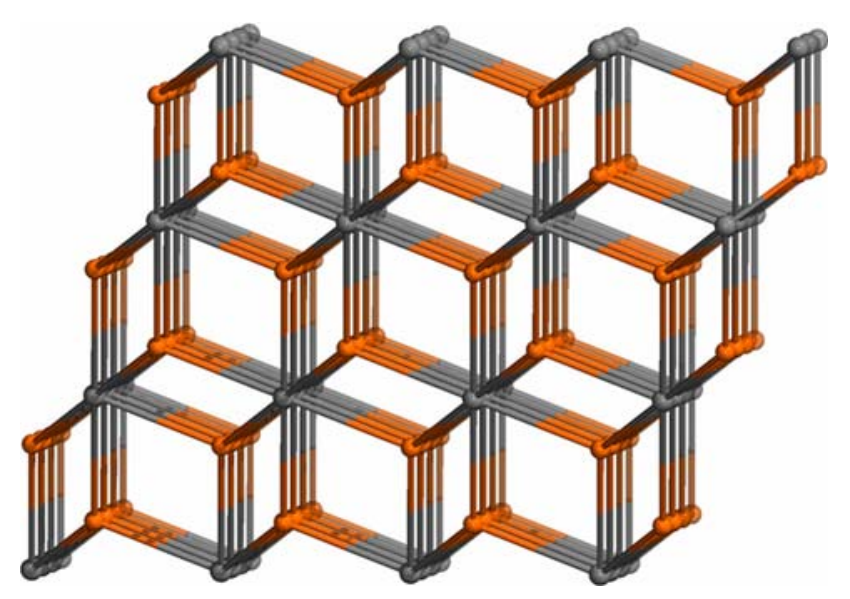

Figure 3. The topology structure of $3 \mathrm{D}$ porous framework in 1.

displayed good electrocatalytic activity towards the reduction of $\mathrm{IO}_{3}^{-}$in $0.5 \mathrm{M} \mathrm{H}_{2} \mathrm{SO}_{4}-\mathrm{Na}_{2} \mathrm{SO}_{4}$ solution $(\mathrm{pH}=2.75)$. With the addition of $\mathrm{IO}_{3}^{-}$, the cathodic peak II substantially increased, while the corresponding anodic peak current decreased. The inset of Figure 5 shows the relationship between the cathodic peak currents of the second wave and concentration of $\mathrm{IO}_{3}^{-}$. The electrocatalytic efficiency of 1 (based on a rough calculation using CAT formula ${ }^{34}$ ) toward the reduction of $\mathrm{IO}_{3}^{-}$was $\mathrm{ca} .190 \%$ at

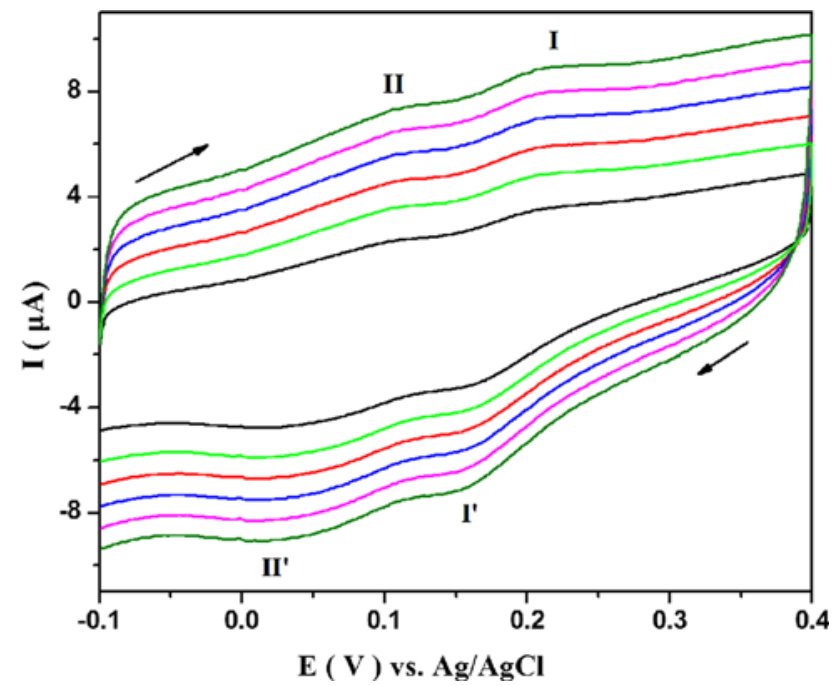

Figure 4. Cyclic voltammograms for $\mathbf{1}$ in $0.5 \mathrm{M}$ $\mathrm{H}_{2} \mathrm{SO}_{4}-\mathrm{Na}_{2} \mathrm{SO}_{4}$ solution at different scan rates (from inner to outer): $0.1,0.2,0.3,0.4,0.5,0.6 \mathrm{~V} \mathrm{~s}^{-1}$.

$0.5 \mathrm{M} \mathrm{H}_{2} \mathrm{SO}_{4}-\mathrm{Na}_{2} \mathrm{SO}_{4}$ solution $(\mathrm{pH}=2.75)$ containing $70 \mathrm{mM}$ iodate.

Additionally, the stability of $\mathbf{1}$ was investigated by scanning for 50 cycles in $0.5 \mathrm{M} \mathrm{H}_{2} \mathrm{SO}_{4}-\mathrm{Na}_{2} \mathrm{SO}_{4}$ solution $(\mathrm{pH}=2.75)$. As shown in Figure 6, it can be seen that the electrode exhibits almost no loss in the current signal after 50 cycles, which suggests that catalyst $\mathbf{1}$ has high stability. 


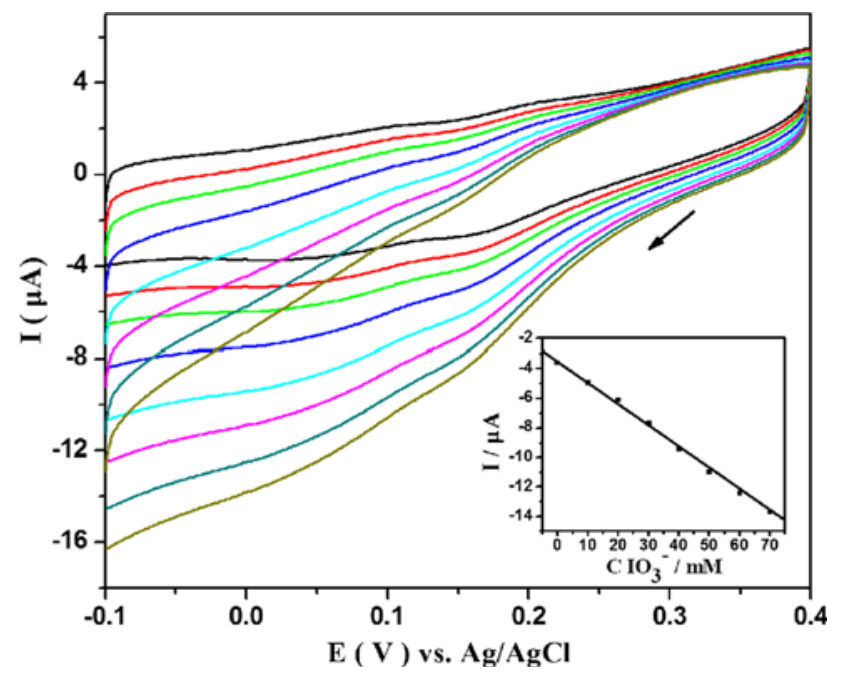

Figure 5. Reduction of $\mathrm{IO}_{3}^{-}$at 1 in $0.5 \mathrm{M} \mathrm{H}_{2} \mathrm{SO}_{4}-\mathrm{Na}_{2} \mathrm{SO}_{4}$ solution $(\mathrm{pH}=2.75)$ containing $\mathrm{IO}_{3}^{-}$in various concentrations (from inner to outer): $0,10,20,30,40,50,60$, and $70 \mathrm{mM}$. The inset shows a linear dependence of the cathodic catalytic current of wave II with $\mathrm{IO}_{3}^{-}$concentration, respectively.

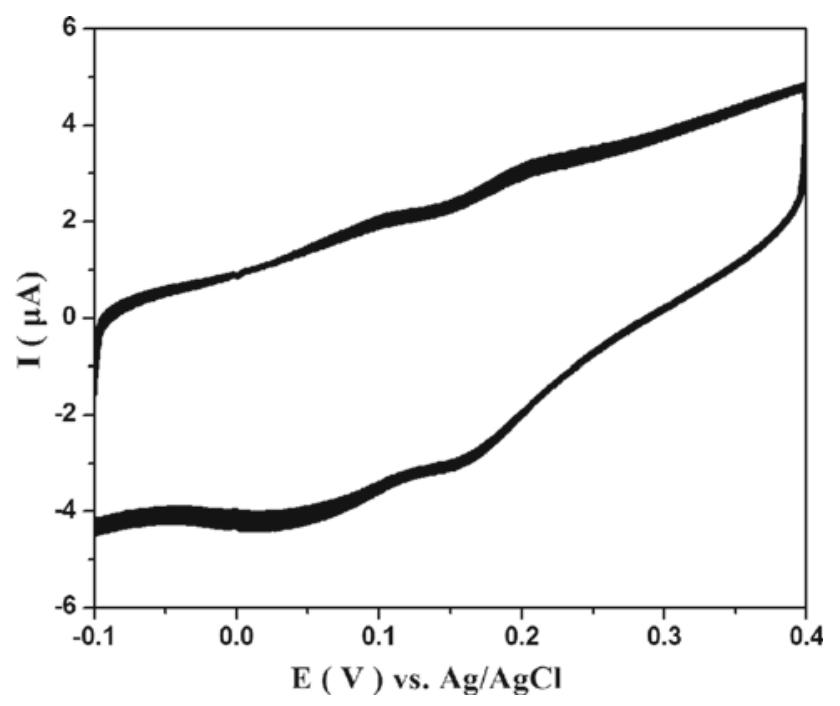

Figure 6. The 50 consecutive $\mathrm{CV}$ cycles of $1-\mathrm{CPE}$ at the scan rate of $0.1 \mathrm{~V} \mathrm{~s}^{-1}$.

\section{Conclusions}

To sum up, a new POM-based 3D porous nanocage framework $\left(\mathrm{H}_{2}\right.$ dap $)\left[\mathrm{K}\left(\mathrm{H}_{2} \mathrm{O}\right)_{2}\left(\mathrm{~V}_{10} \mathrm{O}_{28}\right)_{0.5}\right]$ (1) has been synthesized. In the structure of $\mathbf{1}$, two dap ligand molecules occupy in each POM-based inorganic nanocage. Furthermore, the electrochemical properties of $\mathbf{1}$ were studied, which indicate that $\mathbf{1}$ has good electrocatalytic activity towards reduction of iodate. Synthesis and property investigations on such POM-based 3D porous nanocage framework are in progress in our group.

\section{Supplementary Information (SI)}

Crystallographic data (excluding structure factors) for the structure in this paper have been deposited with the Cambridge Crystallographic Data Centre, CCDC, 12 Union Road, Cambridge CB21EZ, UK. Copies of the data can be obtained free of charge on quoting the depository numbers CCDC number: 784651 or 1 (Fax: +44-1223-336-033; E-mail:deposit@ccdc.cam.ac.uk, http://www.cam.ac.uk).

\section{Acknowledgements}

This work was financially supported by the NSF of China (No. 21603113), the NSF of Heilongjiang Province (No. QC2016014) and Undergraduate Training Programs for Innovation and Entrepreneurship of Qiqihar University (No. 201610221088).

\section{References}

1. Koblenz T S, Wassenaar J and Reek J N H 2008 Reactivity within a confined self-assembled nanospace Chem. Soc. Rev. 37247

2. Sava D F, Kravtsov V C, Eckert J, Eubank J F, Nouar F and Eddaoudi M 2009 Exceptional stability and high hydrogen uptake in hydrogen-bonded metal-organic cubes possessing ACO and AST zeolite-like topologies J. Am. Soc. Chem. 13110394

3. Clever G H, Tashiro S and Shionoya M 2009 Inclusion of anionic guests inside a molecular cage with palladium(II) centers as electrostatic anchors Angew. Chem. Int. Ed. 48 7010

4. Murase T, Nishijima Y and Fujita M 2012 Cagecatalyzed Knoevenagel condensation under neutral conditions in water J. Am. Soc. Chem. 134162

5. Jin Y H, Wang Q, Taynton P and Zhang W 2014 Dynamic covalent chemistry approaches toward macrocycles, molecular cages, and polymers Acc. Chem. Res. 471575

6. Tu B B, Pang Q Q, Ning E L, Yan W Q, Qi Y, Wu D F and Li Q W 2015 Heterogeneity within a mesoporous metalorganic framework with three distinct metal-containing building units J. Am. Soc. Chem. 13713456

7. Qiu X, Zhong W, Bai C H and Li Y W 2016 Encapsulation of a metal-organic polyhedral in the pores of a metal-organic framework J. Am. Soc. Chem. 1381138

8. Du D Y, Qin J S, Li S L, Su Z M and Lan Y Q 2014 Recent advances in porous polyoxometalate-based metal-organic framework materials Chem. Soc. Rev. $\mathbf{4 3}$ 4615

9. Fang X K, Kögerler P, Isaacs L, Uchida S and Mizuno N 2009 Cucurbit $[n]$ uril-polyoxoanion hybrids $J$. Am. Chem. Soc. 131432

10. Han X B, Li Y G, Zhang Z M, Tan H Q, Lu Y and Wang E B 2015 Polyoxometalate-based nickel clusters as visible light-driven water oxidation catalysts $J$. Am. Chem. Soc. 1375486

11. Dolbecq A, Dumas E, Mayer C R and Mialane P 2010 Hybrid organic-inorganic polyoxometalate compounds: 
from structural diversity to applications Chem. Rev. 110 6009

12. Long D L, Burkholder E and Cronin L 2007 Polyoxometalate clusters, nanostructures and materials: From self assembly to designer materials and devices Chem. Soc. Rev. 36105

13. Wang S S and Yang G Y 2015 Recent advances in polyoxometalate-catalyzed reactions Chem. Rev. 115 4893

14. Sun M, Zhang J Z, Putaj P, Caps V, Lefebver F, Pelletier J and Basset J M 2014 Catalytic Oxidation of Light Alkanes $\left(\mathrm{C}_{1}-\mathrm{C}_{4}\right)$ by Heteropoly Compounds Chem. Rev. 114 981

15. Yin Q S, Tan J M, Besson C, Geletii Y V, Musaev D G, Kuznetsov A E, Luo Z, Hardcastle K I and Hill C L 2010 A fast soluble carbon-free molecular water oxidation catalyst based on abundant metals Science $\mathbf{3 2 8}$ 342

16. Hill C L 1998 Introduction: Polyoxometalatesmulticomponent molecular vehicles to probe fundamental issues and practical problems Chem. Rev. 981

17. Kamata K, Nakagawa Y, Yamaguchi K and Mizuno N 2008 1,3-Dipolar cycloaddition of organic azides to alkynes by a dicopper-substituted silicotungstate J. Am. Chem. Soc. 13015304

18. Kuang X F, Wu X Y, Yu R M, Donahue J P, Huang J S and Lu C Z 2010 Assembly of a metal-organic framework by sextuple intercatenation of discrete adamantane-like cages Nat. Chem. 2461

19. Zheng S T, Zhang J, Li X X, Fang W H and Yang G Y 2010 Cubic polyoxometalate-organic molecular cage $J$. Am. Chem. Soc. 13215102

20. Wang X L, Li Y G, Lu Y, Fu H, Su Z M and Wang E B 2010 Polyoxometalate-based porous framework with perovskite topology Cryst. Growth Des. 104227

21. Du D Y, Qin J S, Sun Z, Yan L K, Okeeffe M, Su Z M, Li S L, Wang X H and Lan Y Q 2013 An unprecedented (3, $4,24)$-connected heteropolyoxozincate organic framework as heterogeneous crystalline Lewis acid catalyst for biodiesel production Sci. Rep. 32616

22. Yang D H, Liang Y F, Ma P T, Li S Z, Wang J P and Niu J Y 2014 Ligand-directed conformation of inorganicorganic molecular capsule and cage Inorg. Chem. 53 3048

23. Sheldrick GM 2010 SHELXTL (version 6.1) (Madison, WI: Bruker Analytical, X-ray Instruments Inc.)
24. Brown I D and Altermatt D 1985 Bond-valence parameters obtained from a systematic analysis of the inorganic crystal structure database Acta Crystallogr. B 41244

25. Correia I, Avecilla F, Marcao S and Pessoa J C 2004 Structural studies of decavanadate compounds with organic molecules and inorganic ions in their crystal packing Inorg. Chem. Acta 3574476

26. Kumagai H, Arishima M, Kitagawa S, Ymada K, Kawata S and Kaizaki S 2002 New hydrogen bond-supported 3-D molecular assembly from polyoxovanadate and tetramethylbiimidazole Inorg. Chem. 411989

27. Li T H, Lv J, Gao S Y, Li F and Cao R 2007 Inorganicorganic hybrid with 3D supramolecular channel assembled through $\mathrm{C}-H \cdots \mathrm{O}$ interactions based on the decavanadate Chem. Lett. 36356

28. Nakamura S and Ozeki T 2001 Hydrogen-bonded aggregates of protonated decavanadate anions in their tetraalkylammonium salts J. Chem. Soc. Dalton. Trans. 472

29. Qi Y F, Wang E B, Li J and Li Y G 2009 Two organicinorganic poly(pseudo-rotaxane)-like composite solids constructed from polyoxovanadates and silver organonitrogen polymers J. Solid State Chem. 1822640

30. Ma H Y, Meng X, Sha J Q, Pang H J and Wu L Z 2011 Synthesis, crystal structure and properties of a new bi-dentate decavanadate $\left[\mathrm{Cu}(\mathrm{en})_{2} \mathrm{H}_{2} \mathrm{O}_{2}\left[\mathrm{H}_{2} \mathrm{~V}_{10} \mathrm{O}_{28}\right]\right.$. $12 \mathrm{H}_{2} \mathrm{O}$ Solid State Sci. 13850

31. Wang X L, Gao Q, Tian A X, Hu H L and Liu G C 2012 Effect of the Keggin anions on assembly of $\mathrm{Cu}^{\mathrm{I}}$-bis(tetrazole) thioether complexes containing multinuclear $\mathrm{Cu}^{\mathrm{I}}$-cluster J. Solid State Chem. 187219

32. Keita B, Oliveira P D, Nadjo L and Kortz U 2007 The Ball-Shaped Heteropolytungstates $\left[\left\{\mathrm{Sn}\left(\mathrm{CH}_{3}\right)_{2}\left(\mathrm{H}_{2} \mathrm{O}\right)\right\}_{24}\left\{\mathrm{Sn}\left(\mathrm{CH}_{3}\right)_{2}\right\}_{12}\left(A-\mathrm{XW}_{9} \mathrm{O}_{34}\right)_{12}\right]^{36-}$ $(\mathrm{X}=\mathrm{P}$, As): Stability, Redox and Electrocatalytic Properties in Aqueous Media Chem. Eur. J. 135480

33. Pichon C, Mialane P, Dolbecq A, Marrot J, RiviLre E, Keita B, Nadjo L and Secheresse F 2007 Characterization and electrochemical properties of molecular icosanuclear and bidimensional hexanuclear $\mathrm{Cu}(\mathrm{II})$ azido polyoxometalates Inorg. Chem. 465292

34. Keita B, Belhouari A, Nadjo L and Contant R 1995 Electrocatalysis by polyoxometalate/vbpolymer systems: Reduction of nitrite and nitric oxide J. Electroanal. Chem. 381243 